\title{
ESTRATÉGIAS ESPACIAIS NA PARADA LGBT EM GOIÂNIA, GOIÁS'
}

\author{
SPATIAL STRATEGIES IN THE LGBT PRIDE IN GOIÂNIA, GOIÁS \\ STRATÉGIES SPATIALES LA LGBT PARADE À GOIÂNIA, GOIÁS \\ Jorgeanny de Fátima R. Moreira - Universidade Federal do Vale do \\ São Francisco - Senhor do Bonfim - Bahia - Brasil \\ jorgeanny.moreira@univasf.edu.br
}

\begin{abstract}
Carlos Eduardo Santos Maia - Universidade Federal de Juiz de Fora - Juiz de Fora - Minas Gerais - Brasil carlmaia@uol.com.br
\end{abstract}

\begin{abstract}
Resumo
As reflexões desenvolvidas neste artigo referem-se às análises realizadas sobre as estratégias espaciais e as microterritorialidades efêmeras que se estabelecem no espaço público de Goiânia durante o principal evento voltado para o público LGBT (Lésbicas, Gays, Bissexuais e Transexuais) do Estado de Goiás: a Parada LGBT. Com base em leituras que se preocupam com os temas territorialidades, microterritorialidades e estratégias espaciais, desenvolvemos conceitos que buscam explicar esses fenômenos como mecanismos importantes para a manutenção do evento, que em suas características efêmeras, consegue permanecer no espaçotempo da cidade. Além da revisão bibliográfica, realizamos trabalho de campo em três edições do evento. Nessas incursões utilizamos a observação participante e as entrevistas semiestruturadas como ferramentas metodológicas. Com base nessa breve contextualização, permite-se pensar as paradas como movimentos sociais e, ao mesmo tempo, entendê-las como possibilidades de ativismo, de participação política e de organização social dos indivíduos que podem representar a inversão das atuais formas de poder.

Palavras-chave: Festa popular, visibilidade, ajuntamento político, resistência.
\end{abstract}

\section{Abstract}

The reflections developed in this paper refer to the analyzes of spatial strategies and micro- territoriality settling in public space during the main event for the LGBT (Lesbian, Gay, Bisexual and Transgender) of the State of Goiás: LGBT Parade. Based on readings that are concerned with concepts of territoriality, microterritoriality and spatial strategies, we have developed concepts that attempt to explain these phenomena as important mechanisms for the maintenance of the event, in its ephemeral characteristics, can stay in the city of space-time. Besides the review, conducted fieldwork in three editions of the event. In raids in the event the methodology that we used were the participant observation and semi-structured interviews. Based on this brief background, it is allowed to think the charts like social movements and, at the same time, understand them as activism opportunities, political participation and social organization of individuals who can represent the reversal of the current forms of power.

Keywords: Popular party, visibility, political gathering, resistance.

\section{Résumé}

Les réflexions développées dans cet article sont à propos des stratégies spatiales et des microterritorialités éphémères qui s'établissent dans l'espace public à Goiânia pendant le principal 'événement orientée vers la communauté LGBT (lesbiennes, gays, bisexuels et transgenres) de l'État de Goiás: la LGBT Pride. A partir des lectures sur les concepts de territorialités, micro-territorialités et stratégies spatiales, nous avons développé des concepts qui tentent d'aborder ces phénomènes comme des mécanismes importants pour l'occurrence de l'événement, lequel dans ses caractéristiques éphémères se développe dans l'espace-temps de la ville. 
Au-delà d'une étude bibliographique et aussi recherches sur le terrain dans trois éditions de la fête avec observation participante et des entretiens semi-structurés. Sur la base de ce bref historique, il est permis de penser les parades comme mouvements sociaux et dans le même temps, les comprendre comme des possibilités d'activisme, participation politique et organisation sociale où les individus peuvent représenter l'inversion des formes actuelles du pouvoir.

Mots clés: fête populaire, visibilité, rassemblement politique, résistance.

Introdução

A Parada LGBT (Lésbicas, Gays, Bissexuais e Transexuais) de Goiânia, Goiás, aconteceu pela primeira vez em 1996, à maneira de manifesto organizado pela Associação Ipê Rosa contra a opressão e a discriminação aos homossexuais, contando com apenas nove pessoas, ou oito, o que varia segundo as fontes consultadas (Maia, 2015). O manifesto consistiu na emissão de palavras de ordem junto ao Monumento das Três Raças, na Praça Cívica (espaço simbólico por abrigar a sede do Governo do Estado de Goiás), sendo ainda noticiado que às 9h30, naquela Praça, haveria o ato de "vestir a estátua das Três Raças de roupas GLS (Gays, Lésbicas e Simpatizantes)" e, às 20h30, ocorreria uma Festa Junina Gay, no Castelinho, monumento situado no Setor Oeste em Goiânia (MOVIMENTO GLS COMEMORA DIA DE ORGULHO GAY, 1996, p. 2).

O protesto aconteceu no dia 28 de junho (Dia Mundial do Orgulho Gay) daquele ano ancorado em pedidos de liberdade e tolerância à comunidade goianiense. Desde então, o evento ocorre anualmente em espaços previamente selecionados e que contenham algum conteúdo simbólico para a população da capital e para o segmento LGBT. As estratégias espaciais estabelecidas no espaço público de Goiânia durante o evento são o tema deste artigo. Além disso, algumas reflexões teóricas sobre territorialidades e microterritorialidades são trazidas para este texto e seguem a matriz apresentada pela teoria de Sack (2012) acerca das territorialidades humanas. As leituras de autores como Fortuna (2012), Heidrich (2013) e Turra Neto (2013) foram imprescindíveis para a abordagem conceitual das microterritorialidades capazes de contemplar os processos de dissidência e de efemeridade em sua construção. As estratégias espaciais, processo apontado pelos organizadores e participantes do evento, são analisadas a partir de Robaina (2011), Leão (2014) e Moreira (2013).

Na contextualização teórica, tratam-se ainda as paradas LGBTs como festas onde se manifestam possibilidades de ativismo, ou melhor, 
de "artivismo", de participação política e de organização social dos indivíduos, que podem representar a inversão das atuais formas de poder. Trazer esse diálogo é um esforço em construir uma base teórico-conceitual e metodológica que parte das forças dos indivíduos que lutam por direitos e visibilidade social.

Algumas metodologias foram utilizadas em trabalho de campo, realizado em três edições (2013, 2014 e 2015) da Parada LGBT de Goiânia, entre elas a observação participante e as entrevistas semiestruturadas constituídas por perguntas abertas e fechadas previamente elaboradas (Matos; Pessôa, 2009). As questões abertas permitiram que os entrevistados discorressem sobre o assunto espontaneamente, de forma que uma pergunta gerava outras indagações. Para o tratamento dessas informações coletadas foi utilizada a análise do conteúdo. De acordo com Bardin (2011), é necessário estabelecer quadros de resultados e diagramas que coloquem em evidência as informações que contenham maior referência entre todos os entrevistados.

\section{Da Festa às Estratégias Espaciais na Parada LGBT em Goiânia}

A realização de paradas LGBTs, mundialmente, tem caráter festivo relacionado a um leitmotiv: "celebração do orgulho gay". Pode-se então dizer que entre aqueles três grandes tipos de festas apresentados por Di Méo (2001), as paradas LGBTs são exemplos de "festas comemorativas", notando-se que o autor destaca ainda a existência de eventos cronôminos e patronais. É redundante dizer que as paradas, sendo festas, possuem uma dimensão política, posto que isto é dado ontologicamente às festas em seu modo de ser e, no caso específico das paradas, redunda em "artivismo". A "componente política" das festas expõe relações em que

[...] a autoridade dispõe da possibilidade de utilizar judiciosamente as festas, organizando-as por si própria e submetendo-as à sua estreita regulação. Sem lhes retirar o carácter espontâneo e inevitável de algazarra e desordem, mantém-se atenta para que nada disso degenere em tumulto. Determina os locais, as durações, os participantes, os itinerários (...). Normalmente, a festa engloba também o regresso ritual aos "bons costumes" (Molet, 1998, p. 286).

À maneira de "artivismo", as paradas rompem com o "uso judicioso" anteriormente citado, pois o artivismo 
Apela a ligações, tão clássicas como prolixas e polémicas entre arte e política, e estimula os destinos potenciais da arte enquanto ato de resistência e subversão. Pode ser encontrado em intervenções sociais e políticas, produzidas por pessoas ou coletivos, através de estratégias poéticas e performativas... (Raposo, 2015, p. 5)

Na parada goianiense, a regulação pela autoridade legal, por um lado, notada na determinação dos horários de início e fim do evento, do local de concentração, no controle do trânsito e, às vezes, no recurso à violência contra os participantes (Maia, 2015); e algazarra e "desordem", por outro, pois "a festa dá ao indivíduo a sensação de sair do quotidiano e das suas restrições” (Molet, 1998, p. 286), impele reflexões acerca de estratégias espaciais. Já o "artivismo" perpassa as ações perfomativas, "pela proposição de cenários, paisagens e ecologias alternativas de fruição, de participação e de criação artística” (Raposo, 2015, p. 5) durante a festa.

Os conceitos que se referem às estratégias espaciais remetem às ideias que coadunam com a busca por melhores sítios e localizações para o setor produtivo, econômico, político e social. Leão (2014) explica que as estratégias espaciais são escolhas de ocupação do espaço necessárias para que o indivíduo possa satisfazer suas necessidades básicas para a sobrevivência, tais como alimentação, saúde, lazer, abrigo, amizade etc. Sobre estratégias espaciais, Robaina (2011, p. 170) argumenta que os indivíduos "acabam produzindo estratégias espaciais de sobrevivência diante das possibilidades, e principalmente frente aos elementos hostis que se apresentam cotidianamente". Para o autor, nesses casos, as estratégias estão associadas às ações de defesa e adaptação. Todavia, Robaina (2011, p. 170) reconhece o sentido dual das estratégias espaciais, em que se situam a visibilidade e a invisibilidade, a fixação e a mobilidade espacial que "se constrói a partir da utilização dos próprios elementos que compõem a paisagem dos espaços públicos".

Em uma perspectiva pós-colonial, e com forte influência da geografia feminista, Moreira (2013) abordou as estratégias espaciais de um grupo de mulheres sem teto no Centro do Rio de Janeiro. Em seu trabalho, a autora discorre sobre a criação de territórios íntimos em um ambiente residencial coletivo, resultado da ocupação de um prédio desabitado na capital carioca, para expressar a sexualidade e a individualidade longe dos olhares dos filhos e dos outros habitantes do local. Ademais, essas mulheres desenvolviam estratégias espaciais para contornar as suas 
precárias condições materiais e tornar pequenos espaços de públicos e coletivos em privados e individuais.

Os textos elaborados por estes autores clarificam questões relativas às estratégias espaciais e estão em sintonia com o que se almeja refletir sobre como se dão as ações dos indivíduos comuns, dissociados dos interesses privados dos complexos industriais e comerciais, nesse processo que visa à ocupação do espaço público com o objetivo de alcançar a visibilidade social ou o direito de fazer uso daquilo que pertence ao coletivo, mas que é regido por códigos e normas, bem como pela violência respaldada em certa concepção de "autoridade".

Destarte, em sentido próximo ao que foi proposto pelos autores acima citados, busca-se caracterizar a apropriação e o controle dos espaços públicos por indivíduos que lutam pela transformação política e social, ainda que isto se dê na efemeridade da festa, por meio da ocupação de espaços estratégicos da cidade, uma vez que estes possibilitarão aos/às atores/atrizes sociais: visibilidade em um evento passageiro.

Além disso, cabe ressaltar que o evento estudado transcende essa questão, uma vez que ele envolve o festar, sendo isto entendido por muitos participantes como um momento de descontração e socialidade ${ }^{\mathrm{ii}}$. Este jogo entre conservadorismo e transformação, violência e alegria, autoridade e individualidade nos faz estabelecer um paralelo dramático e metafórico entre as estratégias espaciais constituídas na parada com aquelas ambivalências que Bakhtin (1996, p. 189) assinala no "espírito da festa” em Rabelais, em que "a destruição e o destronamento estão associados ao renascimento e à renovação, a morte do antigo está ligada ao nascimento do novo, todas as imagens são concentradas sobre a unidade contraditória do mundo que agoniza e renasce”.

Trazendo-se o conceito de estratégias espaciais para a Geografia Cultural, busca-se refletir acerca da delimitação das fronteiras dos espaços urbanos do Centro de Goiânia de forma a garantir visibilidade, acessibilidade e mobilidade em um contexto de transformação social pautada na socialidade espacial. Ao contrário daquele conceito voltado para algo fixo, as estratégias espaciais aqui são tratadas na perspectiva do evento, das manifestações que são efêmeras, que possuem algumas horas de duração e que são espacialmente configuradas num trajeto dado em termos de concentração-desfile-dispersão; mas que se repetem todos os anos, as vezes apresentando mudanças paralelamente a certas resistências e inércias, e nas expressões das individualidades pela corporeidade. 
Acerca da "lógica espacial" da permanência da festa nas avenidas selecionadas (Araguaia, Paranaíba, Tocantins), nota-se que estas concentram os fluxos comercial e social da cidade. São avenidas que apresentam um denso número de edificações voltadas à dinâmica comercial e econômica da cidade, havendo inúmeras lojas varejistas de produtos variados, restaurantes, hotéis, camelódromos, ambulantes, hospitais, cursos pré-vestibulares, empresas.

O movimento nessas avenidas é constante até o anoitecer, quando são minimizados os burburinhos da vida urbana, já que o comércio fecha suas portas. Mas ainda assim o fluxo de automóveis e de pedestres, em virtude das instituições de ensino e empresas, é bastante significativo. Não por acaso, os entrevistados, tanto participantes como organizadores da Parada LGBT, elencam a visibilidade, em decorrência do movimento dessas avenidas, como uma das estratégias de as selecionarem para o evento.

Outros fatores foram lembrados pelos entrevistados como estratégicos para a escolha desses espaços, como a acessibilidade e a mobilidade. O Centro de Goiânia é considerado de fácil acesso aos participantes, que se deslocam para a festa predominantemente de transporte coletivo. Porém, aos domingos o número de transporte público é limitado. Conforme informações obtidas na Rede Metropolitana de Transporte Coletivo de Goiânia (RMTC) a frota de ônibus coletivos diminui em $50 \%$ nesses dias.

A RMTC atende toda a Região Metropolitana de Goiânia (RMG) que contabiliza 20 municípios. É importante ressaltar que muitos entrevistados afirmam morar em algum desses municípios da RMG. Considerando-se a distância de moradia ao Centro de Goiânia, bem como o tempo de espera e de viagem no transporte coletivo, ainda que pese a redução no número de veículos de transporte público disponíveis nos fins de semana, a mobilidade e acessibilidade estariam parcialmente favorecidas com a festa ocorrendo no local mencionado.

Outra questão levada em consideração pela organização e que contribui para estabelecer a escolha de alguns espaços no Centro de Goiânia para a realização do evento é a dimensão simbólica que esses espaços representam para a capital e para a população goianiense. O desenho inicial de Goiânia foi proposto pelo arquiteto e urbanista Atílio Correia Lima, recém-chegado de Paris, que utilizou a influência da arquitetura art decó para moldar a capital goiana, vislumbrou traçados simples e com amplas vias com a valorização de áreas verdes, canteiros e 
ilhas largas para o uso do espaço público pela população (Figura 1). Dessa forma, ficaram criadas as três principais avenidas que se encontravam em um desenho concêntrico - na Praça Cívica onde se concentrou o Poder Executivo do Estado de Goiás (Moreira, 2010).

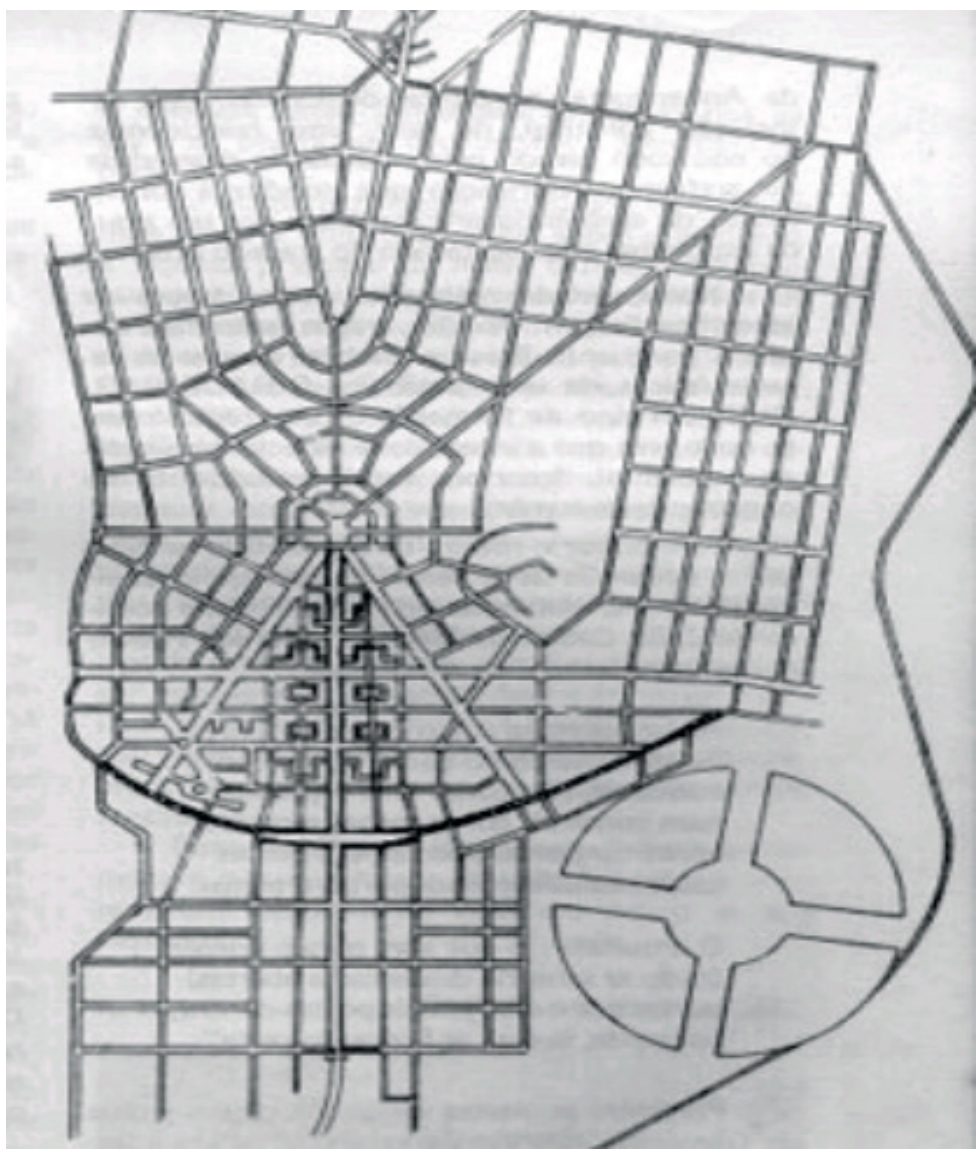

Figura 1 - Plano urbanístico de Goiânia elaborado por Atílio Correia Lima em 1933

Fonte: PUC, GO. Disponível em: <http://www2.ucg.br/arq/urbano/5PlanoAttilio.htm>. Acesso em: 13 dez.2015.

Entretanto, mitos são associados à construção de Goiânia, entre eles, o mais comum e difundido entre os goianos é que Atílio Correia Lima, a pedido do então interventor Pedro Ludovico Teixeira, desenhou 
o Centro em homenagem a Nossa Senhora Auxiliadora, em um período em que os goianienses mantinham forte devoção católica. Então, a Praça Cívica significava a cabeça de Nossa Senhora Auxiliadora e as avenidas representavam o seu manto.

Um dos primeiros organizadores da Parada LGBT em Goiânia, sem que tal fato fosse mencionado pela entrevistadora ao longo do diálogo, explicou a escolha do local (Praça Cívica) para a primeira edição do evento em 1996:

Por toda a simbologia que [...] a Praça Cívica representa pra gente. Então, pra todos os movimentos sociais é... todas as grandes manifestações políticas do nosso estado ela acontece na Praça Cívica ... a gente escolheu a Praça Cívica por isso. Não sei se você sabe, mas geograficamente, na questão da geometria, o centro da cidade ... Goiânia foi planejada ... e o centro da cidade foi planejado como o manto de Nossa Senhora né? [...] Então quando foi planejado a cidade de Goiânia, foi planejado com essa simbologia né? É... geométrica e religiosa, então, é ... como cabeça é o centro de todas as discussões políticas e ali tá o poder político maior do Estado que é a sede Palácio das Esmeraldas (Ativista, 23/06/2013).

As palavras do ativista corroboram as observações de Di Méo (2001, p. 53, tradução nossa) acerca da geografia simbólica das festas:

Estas são as disposições topográficas dos lugares, os efeitos de surpresa e de perspectiva que as suas configurações reservam seus enquadramentos arquitetônicos ou paisagísticos que se internalizam nas representações sociais. Eles permeiam os afetos e os sentidos dos participantes do festival. ${ }^{\text {iii }}$

Não existe nenhuma comprovação documental de que o desenho da capital goianiense foi inspirado em uma figura católica ou motivado pela devoção de quem a idealizaram. No entanto, há estudos que mencionam que essa intepretação, dada por alguns moradores, surgiu após a criação da cidade (Mello, 2006). Além disso, apesar desse fato ser de conhecimento geral da população, não há indícios de que as demais manifestações públicas como protestos, movimentos sindicais ou sociais, aconteçam na Praça Cívica pelo mito criado a partir do catolicismo popular, mas por representar outro significado simbólico: o centro político do Estado de Goiás, porque é neste local que se localiza o Palácio das Esmeraldas, o centro administrativo do Estado. 
Sobre as funções da cidade criadas pelos significados simbólicos que alguns elementos representam, Baczko (1985, p. 296) explica que, "a função do símbolo não é apenas instituir uma classificação, mas também introduzir valores, modelando os comportamentos individuais e coletivos". Entende-se, então, que a simbologia desse espaço representa um arcabouço cultural daqueles que o vivenciam e que o constroem a partir de suas experiências.

Contrariando aquilo que foi narrado pelo primeiro organizador e participante ativo de todas as edições da Parada LGBT de Goiânia, a equipe organizadora das edições de 2013, 2014 e 2015, além de alguns participantes, apresentam uma explicação diferente na escolha desses locais para a realização do evento. Para eles, a concentração ocorre nessas avenidas indicadas pela organização porque aí se situa o Parque Botafogo, ponto de encontros homoafetivos na região central da capital, aspecto também indicado por Maia (2015; 2012) e Braz (2012).

Dessa forma, ao marcarem o ponto de encontro/concentração em um desses espaços expressou o objetivo de dar visibilidade ao evento, mas, além disso, buscou-se associá-lo aos locais simbólicos e/ou que carreguem um conteúdo simbólico-cultural para a comunidade LGBT, de forma a comunicar à população goianiense sobre a apropriação e ocupação do espaço público da cidade por atores/atrizes sociais que também vivenciam e produzem o espaço urbano. Assim sendo, as microterritorializações do espaço público pela Parada LGBT se dão em dois processos: estratégia espacial e visibilidade na festa. Estratégia para se escolher as localizações que permitam o alcance da visibilidade goianiense em relação às microterritorialidades insurgentes do movimento LGBT em Goiânia.

\section{Conflitos e negociações nas microterritorialidades da Parada LGBT}

Observou-se durante as pesquisas de campo que os espaços selecionados para o evento, baseados nas estratégias espaciais, são delimitados e demarcados pelos limites e fronteiras evidenciando microterritórios. Tais recursos não são apenas tangíveis, mas também simbólicos, como o agrupamento ou ajuntamento por afinidade ideológica e política ou pela orientação sexual dos participantes.

Apesar de haver casos em que indivíduos permanecem sozinhos, é nítida a formação de pequenos ajuntamentos, naquele sentido estabelecido 
por Goffman (2010) em que ocupam uma porção do espaço público a partir de objetivos, causas e motivações comuns. Por exemplo, os grupos dos gays e das travestis, em alguns casos - é importante frisar - não se "misturam", ou mesmo grupos de lésbicas que não possuem afinidades e reafirmam estigmas. Há também casos em que homossexuais mais jovens relatam certo preconceito sobre os mais velhos, ou "másculos" contra os mais "afeminados". Alguns comentários preconceituosos, jocosos ou sarcásticos (inclusive lesbofóbicos, transfóbicos e gerontofóbicos) desferidos pelos próprios gays, travestis e lésbicas contra outrem podem gerar conflitos e discussões que servem para desagregar a aglomeração. São comportamentos controversos, uma vez que, a princípio, o evento tem como uma de suas pautas a luta pelo fim do preconceito contra a "LGBTfobia" e exaltação à diversidade; mas, conforme foi dito, alguns estigmas, naquele sentido estabelecido por Goffman (2013) de relação entre atributo e estereótipo, são reafirmados entre quem participa da parada.

Apesar do que foi observado em campo, as respostas dos participantes sobre a relação entre os indivíduos presentes na Parada LGBT de Goiânia foi, em sua maioria, definida como amigável, ou seja, em suas respostas "não há 'mistura entre eles', mas também não há tensões ou conflitos”. As interações são formadas por afinidades ideológicas ou orientação sexual e o evento tem como causa a luta contra repressões, nesse sentido, assim, "não há a necessidade de indivíduos serem introduzidos em um grupo que não compartilha dos mesmos interesses que os deles" (Administradora de Empresas, 27 anos, 2013).

Após explicar que a relação entre os participantes é "amigável” e que nunca presenciou conflitos ou tensões entre os partícipes da Parada LGBT, um dos entrevistados mostra-se contraditório ao afirmar que: “a presença dos [das] transexuais denigrem a imagem do evento, pois mexem muito com a opinião das pessoas. Mas a cidade deve ser para todos né?" (Estudante, 19 anos, 2013). Nas entrelinhas dessa fala, o depoente acaba expressando algo sobre o que Di Méo (2011) e Maia (2011) advertem. O primeiro nota que há" a imposição de normas heterossexuais coercivas sobre gays e lésbicas”"1 (Di Méo, 2011, p. 24, tradução nossa); já o segundo observa que nas paradas LGBTs embora haja "excessos", também se manifesta uma "consciência conservadora" entre os próprios participantes, com manifestações de censura e intolerância (2011, p. 253-254). 
Outro participante pondera as circunstâncias que presenciou nas últimas três edições, e em seu discurso confirma que os conflitos existem, mas

a diversificação de grupos sociais ligados à Parada é extremamente importante. Até mesmo porque não há lésbicas, gays, bissexuais, travestis e transexuais apenas em um grupo social. E acredito que, muito provavelmente, não são menos ou mais lésbicas, gays, bissexuais, travestis e transexuais por serem de grupos sociais distintos (Administradora de Empresas, 27 anos, Homossexual, 15/09/2013).

Essa afirmação evidencia que os conflitos e tensões entre os partícipes existem. Todavia, a diversidade e quantidade são compreendidas como importantes para a construção do evento e que um mesmo participante pode apresentar afinidades em mais de um ajuntamento ou escolher permanecer sozinho. Além disso, identifica-se nessa fala que mais importante que a multiplicidade de grupos ou ajuntamentos são os motivos e os objetivos de estarem na Parada LGBT.

Para Heidrich (2013b, p. 56), o território representa uma expressão da ação, a relação do ator/atriz com o espaço e da provocação de um com o outro. Segundo o autor, "para reconhecer e identificar o território deve-se procurar compreender o que há nele e a quem pertence, seja uma pessoa ou uma instituição". O território aparece nessas palavras como uma apropriação e compreendido por relações que nele são estabelecidas. Di Méo (2001, p. 2, tradução nossa) nota que "a festa possui [...] a capacidade de produzir símbolos territoriais com um uso social que se estende muito além de sua evolução. Essa festa simbólica abraça e qualifica lugares, sítios e paisagens, monumentos ou edifícios simples." 2

Essas acepções referem-se à ideia de que território não se restringe ao poder do Estado, mas a ação de atores/atrizes sociais nos diversos segmentos da sociedade, inclusive no contexto festivo. Todas as ações projetadas no espaço são marcadas por relações de poder e mesmo que, do ponto de vista de limite e escala, a área está demarcada por intermédio da comunicação e da informação proposta por Raffestin (1993).

Para além do que foi colocado pelo ponto de vista teórico, identificou-se na Parada LGBT, campos de forças, grupos e atores/atrizes sociais que exercem o poder por meio do discurso ou pela importância 
simbólica que representam. No último caso pode-se citar como exemplos a Polícia Militar, a Guarda Municipal e os próprios organizadores do evento.

Os indivíduos que se mantêm próximos aos guardas ou policiais apresentam comportamentos mais contidos no que diz respeito à provocação de conflitos. É rara, segundo os policiais, alguma discussão no entorno em que estão. Quando há alguma ocorrência são em pontos com mais de 300 metros de distância da viatura policial. Isso conduz a refletir sobre a relação entre controle, interdição e exclusão apontada por Foucault (1996) para explicar as relações pautadas no poder. É evidente que a "segurança" aparece no evento como forma de controlar e coagir possíveis desvios de conduta, nesse caso as brigas. A interdição e a exclusão ficam claras quando parte do espaço fica interditado ao acesso dos indivíduos, excluindo os participantes daquele local em que a "segurança" se encontra.

Entende-se que os grupos de policiais e de guardas municipais estabelecem microterritórios que compõem a Parada LGBT e se ali estão é porque aqueles espaços são estratégicos por representarem visibilidade na cidade e que devem ser controlados, além de assegurada a contenção de possíveis desvios de condutas e comportamentos tidos como inaceitáveis no espaço público, bem como a manutenção da certeza do retorno à "ordem” após o evento. Sack (2012, p. 77) explica que, quando o acesso ao lugar é afetado por algum tipo de poder e "se os limites forem usados por alguma autoridade para moldar, influenciar ou controlar atividades", o lugar torna-se território. Berrios Navarro e León Perez (2012) partem da perspectiva apontada por Sack ao argumentarem que o território não é estático, mas dinâmico, sua organização modifica-se com o tempo, é o cenário de relações sociais marcadas pelo poder e resulta-se de uma construção social e pode basear-se em princípios estratégicos.

Alguns participantes narram que é na Parada LGBT que - apesar das relações de conflitos e da presença da polícia intimidar as suas ações -, eles estão entre os seus iguais. Sentem-se acolhidos e confortáveis com a ideia de compartilharem as mesmas ideologias e pensamentos. Mesmo quando indagados sobre as possíveis rivalidades entre os grupos ou indivíduos, eles interpelam sobre a importância de todos, independente da condição, lutarem pelas mesmas causas: criminalização da homofobia, direito à união civil entre pessoas do mesmo sexo, adoção de crianças por casais homoafetivos, entre outros temas. Aqui cabe mais uma vez um paralelo metafórico entre a cena parada e a festa em Rabelais magistralmente analisada por Bakhtin (1996, p. 222, grifo do autor): 
Essa organização é antes de mais nada, profundamente concreta e sensível. Até mesmo o ajuntamento, o contato físico dos corpos, que são providos de um certo sentido. O indivíduo se sente parte indissociável da coletividade, membro do grande corpo popular. Nesse todo, o corpo individual cessa, até um certo ponto de ser ele mesmo [...] Ao mesmo tempo, o povo sente a sua unidade e sua comunidade concretas, sensíveis, materiais e corporais.

Argumentos como esses explicitam as (micro) territorialidades nesses espaços demarcados na Parada LGBT onde se verifica a dialética composicional entre o indivíduo e a coletividade. Heidrich (2013a) explica que a territorialidade fortalece o sentimento de coesão social e as relações que se desenvolvem no território, dando-se pelo conjunto de significados e vivências compartilhadas. As microterritorialidades são entendidas como as ações postas nos microacontecimentos ${ }^{\text {iv }}$ que, de maneira efêmera, são pautadas na socialidade e nos afetos compartilhados pelos indivíduos em determinados eventos insurgentes.

Turra Neto (2013, p. 8) exara que as microterritorialidades remetem a uma microgeografia ${ }^{v}$ e situa-se no contexto da emergência e perspectivas que revalorizam os/as atores/atrizes sociais "não só como determinados pelas estruturas em que se encontram inseridos, mas também como portadores de ações, capazes de tensionar e colocar tais estruturas em movimento". Essas ações referem-se às práticas sociais nos microacontecimentos, entendidos como expressões da vida social.

Ademais, compreendemos que a Parada LGBT é constituída por microterritorialidades em razão das efemeridades das relações, além dos fatores que envolvem o seu acontecimento, refletindo a resistência dos/das atores/atrizes sociais frente aos territórios e discursos de poder. Não desconsideramos que as microterritorialidades partem dos mesmos mecanismos formadores das territorialidades; porém em um contexto mais específico - do microacontecimento de resistência e da dissidência social. Se por um lado as territorialidades baseiam-se em sociabilidades, as microterritorialidades estão ancoradas na concepção de socialidade e de coletividade baseadas na partilha de afetos, sentimentos, na corporeidade e nas emoções.

De acordo com Fortuna (2012, p. 200-201), as microterritorialidades referem-se às "análises sobre o corpo, a memória, as identidades e o seu fim, os sentidos, a afetividade etc., todos objetos sujeitos a espacializações condicionantes do seu significado”. Para o autor, essas associações denotam 
alternatividade e dissidência em relação às formas convencionais de ler o mundo, os discursos e o poder. Mostram-se relativas às contestações de grupos subalternos e/ou marginalizados, às minorias que não se enquadram nos valores convencionais da sociedade. Destarte, são formas de socialidade que acolhem as novas maneiras de ler o mundo e de resistir à organização social institucionalizada, "constituem arenas de práticas e discursividades plurais subalternizadas e resistentes à homogeneização" (Fortuna, 2012, p. 202).

Denez (2012) assinala que as microterritorialidades são ações que representam resistências, de formas e princípios diferentes dos modelos dominantes e se expressam também por meio da multidimensionalidade do "vivido" territorial pelos membros de uma coletividade, conforme igualmente postula Raffestin (1993, p. 158) sobre as territorialidades. As relações sociais também são mediadoras e construtoras das microterritorialidades que se fazem por meio da socialidade dos/das atores/ atrizes que buscam resistir às relações e discursos de poder que se originam nos espaços institucionalizados, mesmo que isso se faça por meio de atritos e tensões entre os membros que compartilham dos mesmos objetivos.

Raffestin (1993) menciona que todas as relações estabelecidas no território são marcadas pelo poder, pois este é inevitável, é impossível manter uma relação que não seja marcada por ele. Nas microterritorialidades do evento, isso se dá mediante a formação dos microterritórios no espaço urbano, a partir de afinidades e motivações de estar no movimento, uma vez que as relações de poder se justificam pela simples existência das fronteiras ou limites impostos pelos diferentes grupos, pois elas marcam tensões (Raffestin, 1993).

Assim sendo, os microterritórios que surgem no espaço público durante a Parada LGBT em Goiânia resultam-se, também, além das estratégias espaciais, das tensões, ou seja, dos conflitos que existem entre os/as atores/atrizes vistos como "minorias" nos territórios centrais, políticos e ideológicos.

Mas são espaços produzidos a partir da contestação dos mecanismos opressores e têm na brevidade do espaço-tempo a sua urgência. As microterritorialidades que surgem na Parada LGBT resultam-se das estratégias espaciais e são efêmeras, porque se fazem no e para o instante, mas compreendemos que os discursos que oprimem não são fugazes, eles permanecem. Concordamos com Heidrich (2013a) quando explica que as microterritorialidades, apesar de caracterizarem-se na transitoriedade e 
efemeridade, podem constituir marcas que permanecem por algum tempo, e isso que gera sua lógica territorial.

\section{Considerações Finais}

A análise das estratégias espaciais na Parada LGBT em Goiânia buscou compreender o fenômeno estudado a partir do indivíduo. Os/as atores/atrizes são ativos na produção dessas microterritorialidades, são detentores/as de um arcabouço cultural, político e ideológico. A partir da visibilidade desses indivíduos na festa, a cidade torna-se palco de insurgência entre aqueles/aquelas, entre outras coisas, a conquista de direitos que são cotidianamente negados.

As estratégias, ao selecionar os espaços para abrigar o evento, são mecanismos, que entre outras coisas, buscam garantir a visibilidade dessas "minorias" microterritorializadas que são oprimidas e silenciadas no cotidiano. Compreendemos, portanto, que a preocupação na escolha de um espaço que apresente um conteúdo simbólico-cultural reflete questões ligadas à visibilidade, ao diálogo e à reflexão que poderão ser levados à sociedade goianiense.

As microterritorialidades postas no espaço urbano "afrontam" os mecanismos e dispositivos de poder, não impedem a opressão e contenção, mas garantem a visibilidade, afetam os olhares de quem vive a cidade. Essa visibilidade pode ser entendida como marcas e permanências do evento que se inicia baseado na efemeridade das relações e das ações. Permanecer no cotidiano, por meio da reflexão e negociação do uso do espaço público, é o início de uma luta que deve permanecer no espaço-tempo da cidade.

\section{Notas}

i Artigo parcialmente baseado na tese de doutorado intitulada Do movimento à festa: as microterritorialidades festivas e efêmeras da Parada LGBT em Goiânia, Goiás, defendida em agosto de 2016 no Instituto de Estudos Socioambientais da Universidade Federal de Goiás (IESA/UFG). Pesquisa financiada pela Coordenação de Aperfeiçoamento Pessoal de Nível Superior (Capes). Bolsista Capes - Processo № 99999.003977/2014-05 referente ao estágio de doutoramento na Faculdade de Ciências Sociais e Humanas da Universidade Nova de Lisboa (Doutorado Sanduíche).

ii Socialidade trata-se da solidariedade de base que une os indivíduos de determinado lugar e que possuam objetivos em comum, não são compromissos permanentes, 
são espontâneos, como interações sociais entre trabalhadores com o intuito de reivindicações, protestos, movimentos sociais, festividades (Maffesoli, 1987).

iii Texto original em francês.

iv Adota-se neste texto o conceito de microacontecimentos apresentado por Mendes (2013, p. 154). Para o autor, os microacontecimentos devem ser entendidos como eventos secundários que se relacionam a um evento motivador. "Microacontecimentos são, por assim dizer, fragmentos, estilhaços do acontecimento principal". A Parada LGBT é um evento que surge a partir de um movimento social de luta pelos direitos e cidadania LGBT.

v Entende-se por microgeografias, os estudos preocupados com os sujeitos sociais, as análises partem do indivíduo e suas expressões e ações no espaço. Refere-se a uma geografia que pode estar mais na ruptura do que em continuidade com a tradição científica e acadêmica; está envolvida com outras ciências sociais, diante de um movimento amplo com o campo de diálogos interdisciplinares, tanto nos temas e sujeitos tomados com objetos de estudo, como nos métodos científicos (Lindón, 2006; Turra Neto, 2013).

\section{Referências}

BACZKO, B. A imaginação social. In: Leach, Edmund et al. Anthropos-Homem. Lisboa, Imprensa Nacional/Casa da Moeda, 1985.

BAKHTIN, M. A Cultura Popular na Idade Média e no Renascimento - o contexto de François Rabelais. 3. ed. Brasília, EdUnB/Hucitec, 1996.

BARDIN, Laurence. Análise de Conteúdo. Tradução Luis Antero Reto e Augusto Pinheiro. São Paulo: Edições 70, 2011.

BERRIOS NAVARRO, M. Del P.; LEÓN PÉREZ, A. Territorialidad y Políticas Públicas. In: REYES RAMOS, Maria Eugenia; LÓPEZ LARA, Álvaro F. (Coord.). Explorando Territorios: una visón desde las ciencias sociales. Universidad Autónoma Metropolitana: Unidad Xochimilco: División de Ciencias Sociales y Humanidades, Departamento de Relaciones Sociales, 2012.

BRAZ, C.; MELLO, L. “Éramos 9 gays, 20 policiais e a imprensa local”: narrativas (de) militantes sobre as paradas do orgulho LGBT em Goiás. In: Guilherme R. Passamani. (Org.). (Contra) pontos - Ensaios de gênero, sexualidade e diversidade sexual - o combate à homofobia. Campo Grande: Editora da Universidade Federal do Mato Grosso do Sul, 2012, v. 1, p. 33-47.

DENEZ, C. C. Os conceitos de Macro e Microterritorialidades: uma análise dos processos relacionais no Assentamento 8 de Abril - Jardim Alegre, RS. In: Campo Território: Revista de Geografia Agrária, v. 7, n. 14, p. 1-22, ago. 2012. Disponível em: <www.seer.ufu.br/index.php/campoterritorio/article/ download/14255/11250>. Acesso em: 25 jul.2016.

DI MÉO. La Géographie en Fêtes. Paris, Ophrys, 2001.

. Les Murs Invisibles: femmes genre et géographie sociale. Paris, Armand Colin, 2011. 
FORTUNA, C. (Micro) territorialidades: metáfora dissidente do social, Terra Plural,v. 6, 2012, p. 199-214.

FOUCAUlT, M. A Ordem do Discurso. São Paulo: Loyola, 1996.

GOBBI, Wanderléia A. O.; PESSÔA, Vera L. S. Pesquisa Qualitativa em Geografia: reflexões sobre o trabalho de campo. In: RAMIRES, Julio C. L.; PESSÔA, Vera L. S. (Org.). Geografia e Pesquisa Qualitativa: nas trilhas da investigação. Uberlândia: Assis, 2009.

GOFFMAN, E. Comportamento em Lugares Públicos. Petrópolis, Vozes, 2010.

. Estigma: notas sobre a manipulação da identidade deteriorada. 4. ed. Rio de Janeiro, LTC, 2013.

HEIDRICH, Á. L. Compartilhamento e Microterritorialidades do Espaço Social Metropolitano. In: Cidades. Vol. 10, n. 17, São Paulo: Unesp: Grupo de Estudos Urbanos, 2013a. Disponível em: <http://revista.fct.unesp.br/index.php/ revistacidades/issue/view/233/showToc >. Acesso em: 25 jul. 2016.

. Território e Cultura: argumento para uma produção de sentido. In:

$\overline{\mathrm{COST}} \overline{\mathrm{A}}$, B. P. da; PIRES, C. L. Z. (Org.). Maneiras de Ler: geografia e cultura. [recurso eletrônico]. Porto Alegre: Imprensa Livre: Compasso Lugar Cultura, 2013b.

LEÃO, J. L. B. C. Estratégias espaciais de sobrevivência urbana vivida pelos semabrigo na cidade do Porto. 2014. 128 f. Tese (Mestrado em Geografia) , Instituto de Ciências Sociais, Universidade do Minho, Porto, Portugal, 2014.

LINDÓN, A. Geografías de la vida cotidiana. In: HIERNAUX, Daniel; LINDÓN, Alicia. (Org.). Tratado de Geografía Humana. Barcelona: Anthropos EditorialMéxico: Universidad Autónoma Metropolitana-Iztapalapa, 2006. p. 356-400.

MAFFESOLI, M. O Tempo Tribos: o declínio do individualismo nas sociedades de massa. Rio de Janeiro: Forense-Universitária, 1987.

MAIA, C. E. S. Cidade e festa: os excessos nas paradas LBTs - reflexões a partir da realidade goianiense. Cidades, v. 8, n 13, São Paulo, Unesp: Grupo de Estudos Urbanos p. 233-261, 2011.

. Festividade e Territorialidades na Parada LGBT Goianiense.Terr@ P̄lural, v. 6, n. 2, p. 273288, 2012.

Go West, In The Open Air: Parada do Orgulho LGBT Goianiense - da repressão à turistificação. Revista Latino-americana de Geografia e Gênero, Ponta Grossa, v. 6, n. 1, p. 200-221, jan./jul. 2015.

MELLO, M. M. de. Goiânia: cidade de pedras e de palavras. Goiânia, Editora da Universidade Federal de Goiás, 2006.

MENDES, C. M. Semiótica e Mídia: uma abordagem tensiva do fait divers. 2013. Tese (Doutorado em Semiótica e Linguística Geral) - Faculdade de Filosofia, Letras e Ciências Humanas da Universidade de São Paulo, Departamento de Linguística, São Paulo, 2013.

MOLET, L. O ano religioso, a festa e os ritmos do tempo. In: POIRIER, Jean. História dos Costumes: o tempo, o espaço e os ritmos. Lisboa, Editorial Estampa, v. 1, 1998, p. 193-290. 
MOREIRA, J. de F. R. Parques Urbanos e Qualidade de Vida: estudo da relação dos visitantes com as áreas verdes de Goiânia. 2010. 80 f. Trabalho de Conclusão de Curso (Planejamento Turístico) - Instituto Federal de Educação, Ciência e Tecnologia de Goiás, IF-Goiás, Goiânia, GO, 2010.

MOREIRA, M. F. Casa e família na geografia: estratégias espaciais de mulheres sem-teto na construção do lar. Espaço e Cultura, UERG, RJ, n. 34, p. 83-122, jul./ dez. 2013.

MOVIMENTO GLS COMEMORA DIA DE ORGULHO GAY. O Popular, 28 jun. 1996, p.2.

RAFFESTIN, C. Por uma Geografia do Poder. São Paulo: Ática, 1993.

RAPOSO, Paulo. "Artivismo": articulando dissidências, criando insurgências, Cadernos de Arte e Antropologia [Online], v. 4, n. 2, 2015. Disponível em: <http://cadernosaa.revues.org/909>. Acesso em: 16 ago. 2017.

RMTC. Rede Metropolitana de Transportes Coletivos. Linhas e trajetos: toda a rede. 2015. Disponível em: <http://www.rmtcgoiania.com.br/linhas-etrajetos/toda-a-rede>. Acesso em: 28 maio 2016.

ROBAINA, I. M. M. A invisibilidade como estratégia espacial das populações de rua na cidade do Rio de Janeiro. Espaço Aberto, PPGG - UFRJ, v. 1, n. 2, p. 167176, 2011.

SACK, R. D. O significado da territorialidade. In: DIAS, Leila Christina; FERRARI, Maristela (Org.). Territorialidades Humanas e Redes Sociais. Florianópolis: Insular, 2. ed., 2012.

SANTOS, C. Território e Territorialidade. In: Revista Zona de Impacto, Porto Velho - RO, v. 13, set./dez. Ano 11, 2009.

TURRA NETO, N. Microterritorialidades nas Cidades: uma introdução à temática. In Cidades. v. 10, n. 17, São Paulo: Unesp: Grupo de Estudos Urbanos, 2013. Disponível em: <http://revista.fct.unesp.br/index.php/revistacidades/ issue/view/233/showToc >. Acesso em: 25 jul. 2016.

Jorgeanny de Fátima R. Moreira - Graduada em Geografia pela Universidade Federal de Goiás e em Planejamento Turístico pelo Instituto Federal de Educação, Ciência e Tecnologia de Goiás. Mestre e Doutora em Geografia pelo Instituto de Estudos Socioambientais da Universidade Federal de Goiás. Atualmente é Professora Adjunta da Universidade Federal do Vale São Francisco (Campus Senhor do Bonfim - BA).

Carlos Eduardo Santos Maia - Bacharel e licenciado em Geografia pela Universidade do Estado do Rio de Janeiro, mestre e doutor em Geografia pela Universidade Federal do Rio de Janeiro. Atualmente é professor associado na Universidade Federal de Juiz de Fora e atua como colaborador no Programa de Pós-Graduação em Geografia do Instituto de Estudos Socioambientais da Universidade Federal de Goiás. 
Contribuição dos autores

Os autores declaram participação da construção e formação conjunta deste estudo por meio da análise e interpretação dos dados, leitura e interpretação do referencial teórico e da redação do texto.

Recebido para publicação em 19 de abril de 2017 Aceito para publicação 01 de junho de 2017 